\title{
EXPLORING THE BEHAVIORAL INTENTION TO USE E-GOVERNMENT SERVICES: VALIDATING THE UNIFIED THEORY OF ACCEPTANCE AND USE OF TECHNOLOGY
}

\author{
Mark Anthony Camilleri \\ University of Malta, Department of Corporate Communication, Faculty of Media and Knowledge Sciences, \\ University of Malta, Msida, Malta
}

\begin{abstract}
This study explores the online users' behavioral intention to utilize the governments' websites and their electronic services. The research methodology validates the measuring items from the unified theory of acceptance and use of technology (UTAUT) to better understand the participants' attitudes toward their performance expectancy, effort expectancy, social norms, facilitating condition and behavioral intention to use the electronic government (e-gov) services. The findings from the structural equations modeling approach reported a satisfactory fit for this study's research model. The results suggest that there were highly significant, direct effects from the UTAUT constructs, where the utilitarian motives predicted the online users' behavioral intentions to use e-gov. Moreover, there were significant moderating influences from the demographic variables, including age, gender and experiences that effected the individuals' usage of the governments' online services. In conclusion, this contribution identifies its limitations and suggests possible research avenues to academia.
\end{abstract}

\section{KEYWORDS}

Unified Theory of Acceptance and Use of Technology, e-Government, Performance Expectancy, Effort Expectancy, Social Norms, Facilitating Conditions

\section{INTRODUCTION}

The information and communication technologies (ICTs) as well as other web-based technologies can enhance the effectiveness, economies and efficiencies of service delivery in the public sector. Therefore, many governments are increasingly using the digital and mobile media to deliver public services to online users (Zuiderwijk Janssen \& Dwivedi. 2015). The electronic government services (e-gov) are facilitators and instruments that are intended to better serve all levels of the governments' operations, including its departments, agencies and their employees as well as individual citizens, businesses and enterprises (Rana $\&$ Dwivedi, 2015). The governments may use information and communication technologies, including computers, websites and business process re-engineering (BPR) to interact with their customers (Isaías, Pífano \& Miranda, 2012; Weerakkody, Janssen \& Dwivedi, 2011). E-gov services involve the transformational processes within the public administration that add value to the governments' procedures and services through the introduction and continued appropriation of information and communication technologies as a facilitator of these transformations. These government systems have improved over the years. In the past, online users relied on one-way communications, including emails. Today, online users may engage in two-way communications, as they communicate and interact with the government via the Internet, through instant-messaging (IM), graphical user interfaces (GUI) or audio/video presentations.

Traditionally, the public services were centered around the operations of the governments' departments. However, e-governance also involves a data exchange between the government and other stakeholders, including the businesses and the general public (Rana \& Dwivedi, 2015). The advances in technology have led to significant improvements in the delivery of service quality to online users (Isaías et al., 2012). As e-government services become more sophisticated, the online users will be intrigued to interact with the 
government as e-services are usually more efficient and less costly than offline services that are delivered by civil servants. However, there may be individuals who for many reasons, may not have access to computers and the internet. Such individuals may not benefit of the governments' services as other citizens. As a result, the digital divide among citizens can impact their socio-economic status (Ebbers, Jansen \& van Deursen, 2016). Moreover, there may be individuals who may be wary of using e-government systems. They may not trust the e-gov sites with their personal information, as they may be concerned on privacy issues. Many individuals still perceive the governments' online sites as risky and unsecure.

This contribution addresses a knowledge gap in academic literature as it examines the online users' perceptions on e-gov systems. It relies on valid and reliable measures from the Unified Theory of Acceptance and Use of Technology (UTAUT) (Zuiderwijk et al., 2015; Wang \& Shih, 2009; Venkatesh, Morris, Davis \& Davis, 2003;2012) to explore the respondents 'attitudes toward performance expectancy, effort expectancy, social influences, facilitating conditions as well as their intentions to use the governments' electronic services. Moreover, this research also investigated how these UTAUT constructs were affected by the demographic variables, including age, gender and experiences. It explains the causal path that leads to the online users' acceptance and use of e-gov.

\section{THE LITERATURE REVIEW AND THE FORMULATION OF HYPOTHESES}

A thorough literature review suggests that there are a number of theoretical frameworks, including; the Theory of Reasoned Action (Fishbein \& Ajzen, 1975), the Technology Acceptance Model (Davis 1989; Davis, Bagozzi \& Warshaw, 1989); the Theory of Planned Behaviour (Ajzen 1991); the Unified Theory of Acceptance and Use of Technology (Zuiderwijk et al., 2015; Venkatesh et al., 2003) among others. Their measures have often been validated in academia; as many researchers have frequently explored the users' engagement with various technologies, in different contexts.

\subsection{The Behavioural Intention to Use Technology}

According to the Technology Acceptance Model, the individuals' behavioural intention to use technology would be determined by their attitude toward usage, which would in turn be conditioned by the usefulness and the ease of use of information systems (Bonanno \& Kommers, 2008; Davis, 1989; Davis et al., 1989). Ajzen and Fishbein's Theory of Reasoned Action (1975) posited that the individuals' behavioural intention is determined by the individual's personal attitude toward the behaviour and by the normative pressures that are experienced by individuals. The normative pressure or the "subjective norm has a direct effect on the individuals' behavioural intention (Camilleri \& Camilleri, 2017; Fishbein \& Ajzen, 1975, p. 302) as individuals may be influenced by others to use technology. Venkatesh et al. (2003) have integrated elements from different theoretical models and empirically validated them in their UTAUT model. They explored how individuals accepted and used technology in their workplace environments. Venkatesh et al. (2003) held that the individuals' performance expectancy, effort expectancy, social influence, and the facilitating conditions were four major constructs that could influence their intention to use technology. They maintained that the behavioral intention had a significant positive influence on technology usage. The users' experience moderates the link between behavioral intention and use (Park, Nam \& Cha, 2012; Wang \& Shih, 2009; Venkatesh et al., 2003). This argumentation leads to the first hypothesis:

H1: The online users' behavioral intention has an effect on their usage of e-gov. The users' experience is a moderator variable in this relationship.

\subsection{Performance Expectancy}

The performance expectancy explains how the users believe that the technology will support them. This construct is related to 'perceived usefulness' (Bonanno \& Kommers, 2008; Davis, 1989; Davis et al., 1989), and to extrinsic motivation (Davis, Bagozzi \& Warshaw, 1992) as it emphasizes the importance of utilitarian value. This construct is tied to utility. Several studies have consistently indicated that performance 
expectancy is the strongest predictor of behavioral intention (see Venkatesh et al. 2003). In Venkatesh et al.'s (2003) own words, performance expectancy is "the degree to which an individual believes that using the system will help him or her to attain gains in job performance" (p. 447). Venkatesh et al. (2003) suggested that the relationship between the adopters' performance expectancy and their intention to use the technology will be moderated by gender and age. These demographic variables can have an effect on the adoption of technology adoption (Camilleri, 2018). This leads to the second hypothesis:

H2: The performance expectancy can influence the individuals' behavioural intention to use e-gov. Age and gender will moderate this effect.

\subsection{Effort Expectancy}

Davis (1989) explored the extent to which a person thinks that the technology is user-friendly and free of effort. He argued that the individuals' perceived ease of use (PEoU) of technology is a precursor of their technology acceptance. Venkatesh et al.'s (2003) 'effort expectancy' construct is very similar to Davis's (PEoU). The authors maintain that; 'effort expectancy is the degree of ease associated with the use of the system'. In simple words, if the technology is easy to use the individuals can benefit from it. As a result, they may be willing to use the technology. Therefore, the effort expectancy (or the technological anxiety) can have an impact on the individuals' intention to use toward technologies. Venkatesh et al. (2012) posited that age, gender and experience may influence the relationship between effort expectancy and behavioural intention to use the technology. This leads to the third hypothesis:

H3: The effort expectancy can influence the individuals' behavioral intention to use e-gov. Age, gender and experience will moderate this effect.

\subsection{Social Influence}

Very often, individuals are influenced by others, including their family and friends, to use the technologies. The social influence (SI) is "the degree to which an individual perceives that important others believe he or she should use the new system" (Venkatesh et al., 2003, p. 451). This construct is similar to Fishbein and Ajzen's (1975) subjective norm construct that was used in their theory of reasoned action as well as in Ajzen's (1991) theory of planned behavior. These theories suggest that social influence is a direct determinant of behavioral intention (Park et al., 2012). Moreover, the demographic variables, including gender may have an influence on the relationship between the social influence and the users' intention to use technology (Camilleri, 2018). The males and female genders may respond in a different manner to the societal pressures as they may be driven by psycho-social phenomena to behave the way they do. Notwithstanding, age and experience may also affect whether individuals rely on social influences (Venkatesh et al., 2012). This leads to the fourth hypothesis.

H4: Social influences can affect the individuals' behavioural intention to use of e-gov. Age, gender and experience will moderate this effect.

\subsection{The Facilitating Conditions}

The users of technology depend on its functionality (Nysveen, Pedersen \& Thorbjørnsen, 2005) and on the structural features of the environment, such as training, support, and access to technology (Teo, 2009). Venkatesh et al. (2003) defined the 'facilitating conditions' construct as "the degree to which an individual believes that an organizational and technical infrastructure exists to support use of the system" (p. 453). Venkatesh et al. (2012) held that this effect increases with experience and with age, as individuals may ask for the support from others. Older individuals may face more difficulty in adopting new technologies (Camilleri \& Camilleri, 2017). Moreover, there may be differences among genders. Therefore, age, gender and experience can moderate the relationship between facilitating conditions and behavioral intention. This leads to the fifth and sixth hypotheses: 
H5: The facilitating conditions significantly influence the individuals' use of e-gov.

H6: The facilitating conditions significantly influence the individuals' behavioral intention to use e-gov. Age, gender and experience will moderate this effect.

\subsection{The Research Model}

This study hypothesizes that the performance expectancy, effort expectancy, social influence, and facilitating conditions are the antecedents of behavioral intention to use e-gov as illustrated in Figure 1.

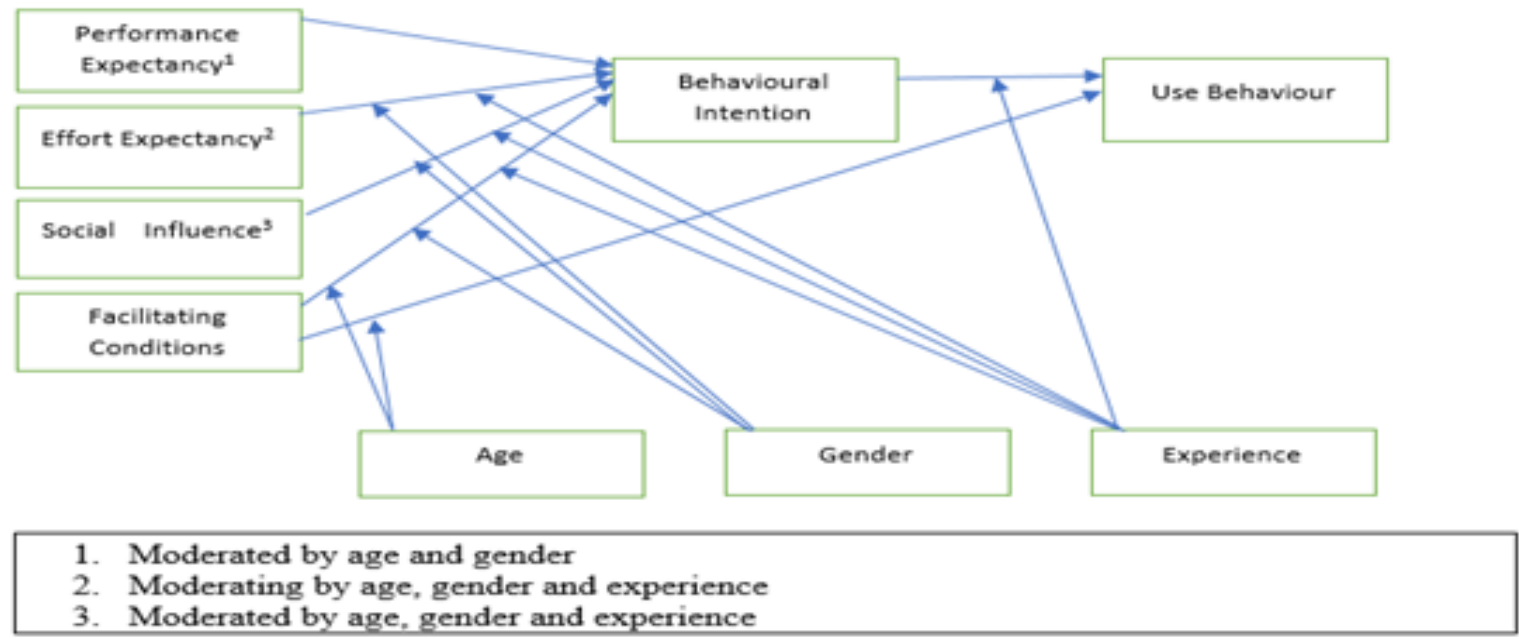

Figure 1. The Unified Theory of Acceptance and Use of Technology Model

\section{METHODOLOGY}

\subsection{The Research Method}

The research participants were selected from a database of 25,300 online shoppers who had subscribed to receive retail information from group of companies, in Edinburgh, Scotland. The researcher sent them emails with a hyperlink to a structured survey questionnaire. The respondents could not participate more than once in the survey as they could not use the same IP address. The emails generated 12,083 hits on the questionnaire's website. Of these, 705 respondents have submitted useable data sets. The respondents could not participate more than once in the survey as they could not use the same IP address.

\subsection{The Measures}

The respondents indicated the extent of their agreement with the survey items, in a seven-point Likert scale. The responses ranged from $1=$ "strongly disagree" to $7=$ "strongly agree", where 4 signaled an indecision. This study adapted valid and reliable measures that were drawn from Venkatesh et al.'s (2003) UTAUT. The constructs included; 'behavioral intention', 'performance expectancy', 'effort expectancy', and 'social influence', and 'facilitating conditions'. Several steps were undertaken to avoid the common method variance (CMV) that is attributed high item characteristics effects (Sharma, Yetton \& Crawford, 2009). The Harman's single-factor test was used to check for "systematic error variances" among variables as correlations could have been affected by CMV as a function of both the method and the particular constructs being measured. 


\subsection{The Research Participants}

The surveyed respondents gave their socio-demographic details about their 'gender', 'age' and 'experience' in the latter part of the survey questionnaire. The research participants were expected to disclose their age by choosing one of seven age groups; They confirmed their gender by choosing the 1 or 0 dummy variable. Moreover, they revealed their experience (that was measured in months) with e-gov systems. Table 1 presents the profile of respondents that participated in this study:

Table 1. The Demographic Profile of Respondents

\begin{tabular}{|l|l|}
\hline \multicolumn{2}{|c|}{ Gender } \\
\hline Female & 474 \\
\hline Male & 232 \\
\hline & \\
\hline $\mathrm{N}=706$ & \\
\hline & \\
\hline & \\
\hline & \\
\hline & \\
\hline & \\
\hline & \\
\hline
\end{tabular}

\begin{tabular}{|l|c|}
\hline \multicolumn{2}{|c|}{ Age } \\
\hline 16-25 years & 105 \\
\hline 26-35 years & 163 \\
\hline 36-45 years & 184 \\
\hline 46-55 years & 165 \\
\hline 56-65 years & 62 \\
\hline 66-75 years & 21 \\
\hline More than 76 years & 3 \\
\hline & \\
\hline mean & 37 years \\
\hline N=703 & \\
\hline
\end{tabular}

\begin{tabular}{|l|c|}
\hline \multicolumn{2}{|c|}{ Experience } \\
\hline 0-12 months & 32 \\
\hline 13-24 months & 27 \\
\hline 25-36 months & 89 \\
\hline 37-48 months & 343 \\
\hline 49-60 months & 190 \\
\hline 61-72 months & 15 \\
\hline More than 73 months & 10 \\
\hline & \\
\hline mean & 44 months \\
\hline N=706 & \\
\hline
\end{tabular}

\section{DATA ANALYSIS}

There were two hundred thirty-two males and four hundred seventy-four females $(n=706)$. The respondents' 'age' varied, and this was evident in the standard deviation $(\boldsymbol{\sigma})$ of 0.79 . Respondents were also classified into six age groups $(16-25 ; 26-35 ; 36-45 ; 46-55,56-65$ and over 66 years of age). The majority of the respondents were aged between 36 and 45 years of age $(n=184)$, followed by those aged between 46 and 55 years $(n=165)$. The majority of respondents $(n=343)$ indicated that they had acquire between $37-48$ months of experience using e-gov. Whereas, two hundred fifteen respondents had used e-gov for more than 4 years. The respondents indicated that they agreed with the survey items in the model, as the mean scores were well above the mid-point of 4.0. Moreover, the standard deviations indicated that there was a narrow spread of participants' responses, ranging from 0.3 to 1.4 , indicating a narrow spread around the mean. The skewness and the kurtosis indices met Kline's (2005) recommendations for the purposes of SEM.

\subsection{Evaluation of the Measurement Model}

The measurement model involved a confirmatory factor analysis (CFA). This was conducted through AMOS 7.0 in order to assess the uni-dimensionality, validity and reliability of the constructs. CFA removed the items that did not fit the measurement model due to low factor loading. The researcher conducted a pooled CFA to assess the measures of the latent constructs. The uni-dimensionality was achieved as all factor loadings were positive and higher than 0.6. There was evidence of convergent validity as all items in the measurement model were statistically significant. The values of the average variance extracted (AVE) were higher than 0.5. Moreover, there was construct validity as the Fitness Indexes of the latent constructs achieved the required level.

\subsection{The Confirmatory Factor Analysis}

The CFA results indicated the fitness indices and the factor loading for every item together with their adj. R2. The correlations between constructs were computed simultaneously. There were certain fitness indices that did not achieve the required level. The factor loading for item PE4 and FC3 were below 0.6. Therefore, these two items were dropped. There was discriminant validity as the model had low modification indices $(\mathrm{MI}<14)$ and the correlation between the exogenous constructs did not exceed 0.85 . The items that had a 
factor loading less than 0.6 and an R2 less than 0.4 were deleted as they affected the fitness index of the model. The fitness indexes have improved after the necessary modifications. The latest results reported a satisfactory model fit: $\left[\chi^{2}=445.240 ; \chi^{2} / \mathrm{df}=2.98 ; \mathrm{TLI}=.961 ; \mathrm{CFI}=.950 ; \mathrm{RMSEA}=.048 ; \mathrm{SRMR}=.029\right.$.

\subsection{The Validity and Reliability of the Research Model}

The Fitness Indices met the required level. This study employed Fornell and Larcker's (1981) comprehensive testing system that is based on measures of explanatory power (shared variance) within the structural model, measurement model and overall model. The Convergent Validity for the measurement model was achieved as all AVE values exceeded 0.7 (i.e. more than the recommended 0.50 threshold). Moreover, the Composite Reliability (CR) exceeded 0.80 , as reported in Table 2 . Table 3 presents the discriminant validity index that indicated the correlation coefficients as well as the AVEs that were presented as off-diagonal elements (in bold).

Table 2. The Confirmatory Factor Analysis

\begin{tabular}{|c|c|c|c|c|}
\hline \multicolumn{2}{|c|}{ Construct and Items } & & FL & $\mathbf{C R}$ \\
\hline Performance & PE1 & I find e-gov useful in my daily life & 0.8 & \multirow{3}{*}{0.82} \\
\hline \multirow{3}{*}{$(\mathrm{AVE}=0.883)$} & PE2 & $\begin{array}{l}\text { Using e-gov increases my chances of achieving } \\
\text { things that are important to me. }\end{array}$ & 0.78 & \\
\hline & PE3 & $\begin{array}{c}\text { Using e-gov helps me accomplish things more } \\
\text { quickly }\end{array}$ & 0.65 & \\
\hline & PE4 & Using e-gov increases my productivity & 0.49 & Deleted \\
\hline \multirow{4}{*}{$(\mathrm{AVE}=0.9)$} & EE1 & Learning how to use e-gov is easy for me & 0.91 & \multirow{4}{*}{0.89} \\
\hline & EE2 & $\begin{array}{l}\text { My interaction with e-gov is clear and } \\
\text { understandable }\end{array}$ & 0.88 & \\
\hline & EE3 & I find e-gov easy to use & 0.86 & \\
\hline & EE4 & It is easy for me to become skilful at using e-gov & 0.9 & \\
\hline \multirow{3}{*}{$\begin{array}{l}\text { Social Influence } \\
\text { (AVE=0.889) }\end{array}$} & SI1 & $\begin{array}{l}\text { People who are important to me think that I should } \\
\text { use e-gov }\end{array}$ & 0.79 & \multirow{3}{*}{0.85} \\
\hline & SI2 & $\begin{array}{l}\text { People who influence my behaviour think that I } \\
\text { should use e-gov }\end{array}$ & 0.92 & \\
\hline & SI3 & $\begin{array}{c}\text { People whose opinions that I value prefer that I use } \\
\text { e-gov }\end{array}$ & 0.87 & \\
\hline \multirow{4}{*}{$(\mathrm{AVE}=0.906)$} & FC1 & I have the resources necessary to use e-gov & 0.88 & \multirow{3}{*}{0.88} \\
\hline & $\mathrm{FC} 2$ & I have the knowledge necessary to use e-gov & 0.85 & \\
\hline & $\mathrm{FC} 4$ & $\begin{array}{l}\text { I can get help from others when I have difficulties } \\
\text { using e-gov }\end{array}$ & 0.74 & \\
\hline & FC3 & e-gov is compatible with other technologies I use & 0.46 & Deleted \\
\hline \multirow{3}{*}{$\begin{array}{l}\text { Behavioural } \\
\text { Intention } \\
(\mathrm{AVE}=\mathbf{0 . 8 8 9})\end{array}$} & BI1 & $\begin{array}{l}\text { It is very likely that I shall continue using e-gov in } \\
\text { the future }\end{array}$ & 0.81 & \multirow{3}{*}{0.91} \\
\hline & $\mathrm{BI} 2$ & Probably, I will use e-gov in my daily life. & 0.82 & \\
\hline & $\mathrm{BI} 3$ & I will use e-gov as frequently as possible. & 0.79 & \\
\hline
\end{tabular}


Table 3. The Discriminant Validity Index

\begin{tabular}{|c|c|c|c|c|c|c|c|c|c|c|c|}
\hline \multicolumn{2}{|c|}{ Construct } & \multicolumn{2}{c|}{ Items } & $\mathbf{1}$ & $\mathbf{2}$ & $\mathbf{3}$ & $\mathbf{4}$ & $\mathbf{7}$ & $\mathbf{8}$ & $\mathbf{9}$ & $\mathbf{1 0}$ \\
\hline 1 & Performance Expectancy & PE & 3 & $\mathbf{0 . 8 8 3}$ & & & & & & & \\
\hline 2 & Effort Expectancy & EE & 4 & $0.512^{*}$ & $\mathbf{0 . 9}$ & & & & & & \\
\hline 3 & Social Influence & SI & 3 & -0.725 & 0.675 & $\mathbf{0 . 8 8 9}$ & & & & & \\
\hline 4 & Facilitating Conditions & FC & 3 & 0.531 & $0.392^{*}$ & 0.712 & $\mathbf{0 . 9 0 6}$ & & & & \\
\hline 7 & Behavioral Intention & BI & 3 & 0.743 & $0.193^{*}$ & 0.723 & -0.743 & $\mathbf{0 . 8 8 9}$ & & & \\
\hline 8 & Gender & GDR & 1 & 0.021 & -0.032 & -0.011 & $0.017^{*}$ & -0.125 & N/A & & \\
\hline 9 & Age & AGE & 1 & 0.111 & -0.015 & -0.011 & -0.003 & 0.005 & $0.012^{*}$ & N/A & \\
\hline 10 & Experience & EXP & 1 & 0.03 & $0.022^{*}$ & -0.017 & $0.011^{* *}$ & 0.104 & $0.101^{*}$ & $0.092^{*}$ & N/A \\
\hline
\end{tabular}

Note: $* \mathrm{p}<0.05 ; * * \mathrm{p}<0.01 ; * * * \mathrm{p}<0.001$; all other correlations are insignificant.

\section{THE RESULTS FROM THE STRUCTURED MODEL}

The findings from the structural equations modeling approach reported a satisfactory fit for this study's research model. The structural model results suggest that there were highly significant, direct effects from the UTAUT constructs, where there were utilitarian motives that have predicted the online users' behavioral intentions to use e-gov. Overall, the direct effects represented 38 percent of the variance that predicts behavioral intention, whilst the interaction terms explained 67 percent of the variance. In a similar vein, there was 41 percent of the variance that can be attributed to the direct effects, and 54 percent of the variance comprised the mediating effects. The findings suggest that performance expectancy had a very significant direct effect $(p<0.001)$ on behavioral intention. There were significant moderating influences from the demographic variables, including age, gender and experiences on other exogenous variables that effected the users' engagement with the e-gov systems.

The behavioural intention had a highly significant influence $(\mathrm{p}<0.001)$ and a direct effect $(0.31)$ on the use of e-gov. There was a significant $(\mathrm{p}<0.05)$, indirect effect $(0.13)$ from the users' experience $(0.13)$ in this BIU-USE (H1) relationship. The performance expectancy had a direct effect $(0.32)$ on behavioral intention, and this influence was highly significant at $\mathrm{p}<0.001(\mathrm{H} 2)$. Notwithstanding, there was an indirect effect (0.11) from the mediating variables, including; age and gender, in the PE-BIU (H2) relationship. Whilst, there were significant direct relationships (referring to H3, H4 and H6), as effort expectancy (0.24) and social influence (0.19) were positively and significantly related with the individuals' behavioral intention to use e-gov, where $\mathrm{p}<0.05$. The facilitating conditions also effected (0.19) the use of this ubiquitous technology. The facilitating conditions (H5) was a very significant antecedent that predicted the use of e-gov, where $\mathrm{p}<0.01$. Venkatesh et al.'s study (2012) also reported a significant direct relationship between FC and BIU. Yet, their study reported that there was no relationship between facilitating conditions and behavioral intention when the moderating effects of age, gender and experience were considered in the structured equation.

The results also suggest that there were indirect relationships as there were significant mediating effects from age, gender, experience. There were other significant path coefficients within the interaction terms, that included the mediating variables like; EXP (0.14), AGE x EXP (0.15), FC x AGE (0.21), FC x EXP (0.24) and FC x GDR x AGE (0.09) that indirectly predicted B1. Similarly, BI x EXP (0.17), FC x AGE (0.12), and FC x AGE x EXP (0.13) predicted the use of e-gov systems. The performance expectancy appears to be a determinant of intention in most situations: the strength of the relationship varies with gender and age such that it is more significant for males and younger respondents. The effect of the moderator variable on the link between social influence and intention was found to be insignificant. However, effort expectancy had an influence on behavioral intention and this link was moderated by gender and age such that it was more significant for females and older respondents. Those effects decreased with experience. 


\section{LIMITATIONS AND FUTURE RESEARCH}

This study has validated Venkatesh et al.'s (2003) unified theory of acceptance and use of technology to explore the users' behavioral intention to use of e-gov. The number of research participants was more than sufficient to draw significant conclusions from the results. However, one of the limitations of this study concerns the skewness of the sampling frame of this research. The respondents in this study were mostly middle-aged females (their mean age was around 37). As a result, the findings of this study may not apply to other demographic groups. Future contributions can replicate this study in different contexts. Perhaps, they can build on this study by including more utilitarian and / or hedonic constructs to explore the effect of other exogenous constructs on the individuals' behavioral intention to use e-gov.

\section{REFERENCES}

Ajzen, I. 1991. The theory of planned behavior. Organizational Behavior and Human Decision Processes, Vol. 50, No. 2, pp. 179-211.

Bonanno, P., \& Kommers, P.A. 2008. Exploring the influence of gender and gaming competence on attitudes towards using instructional games. British Journal of Educational Technology, Vol. 39, No. 1, pp. 97-109.

Camilleri, M.A., \& Camilleri, A.C. 2017. Digital learning resources and ubiquitous technologies in education. Technology, Knowledge and Learning, Vol. 22, No. 1, pp. 65-82.

Camilleri, M.A. 2018. The SMEs' technology acceptance of digital media for stakeholder engagement. Journal of Small Business and Enterprise Development.

https://www-emeraldinsight-com.ejournals.um.edu.mt/doi/full/10.1108/JSBED-02-2018-0042

Davis, F.D. 1989. Perceived usefulness, perceived ease of use, and user acceptance of information technology. MIS Quarterly, pp. 319-340.

Davis, F.D., Bagozzi, R.P., \& Warshaw, P.R. 1989. User acceptance of computer technology: a comparison of two theoretical models. Management Science, Vol. 35, No. 8, pp. 982-1003.

Davis, F. D., Bagozzi, R.P., \& Warshaw, P.R. 1992. Extrinsic and intrinsic motivation to use computers in the workplace 1. Journal of Applied Social Psychology, Vol. 22, No. 14, pp. 1111-1132.

Ebbers, W. E., Jansen, M. G., \& van Deursen, A. J. 2016. Impact of the digital divide on e-government: Expanding from channel choice to channel usage. Government Information Quarterly, Vol. 33, No. 4, pp. 685-692.

Fishbein, M., \& Ajzen, I. 1975. Belief, Attitude, Intention, and Behavior: An Introduction to Theory and Research, Reading, MA, USA: Addison-Wesley.

Fornell, C., \& Larcker, D.F. 1981. Evaluating structural equation models with unobservable variables and measurement error. Journal of Marketing Research, Vol. 48, pp. 39-50.

Isaías, P., Pífano, S., \& Miranda, P. (2012). Web 2.0: Harnessing democracy’s potential. In Public Service, Governance and Web 2.0 Technologies: Future Trends in Social Media (pp. 223-236). IGI Global.

Kline, R.B. 2005. Principles and practice of structural equation modeling (2nd ed.). New York: Guilford Press.

Nysveen, H., Pedersen, P.E., \& Thorbjørnsen, H. 2005. Explaining intention to use mobile chat services: moderating effects of gender. Journal of Consumer Marketing, Vol. 22, No. 5, pp. 247-256.

Park, S.Y., Nam, M.W., \& Cha, S. B. 2012. University students' behavioral intention to use mobile learning: Evaluating the technology acceptance model. British Journal of Educational Technology, Vol. 43, No. 4, pp. 592-605.

Rana, N. P., \& Dwivedi, Y.K. 2015. Citizen's adoption of an e-government system: Validating extended social cognitive theory (SCT). Government Information Quarterly, Vol. 32, No. 2, pp. 172-181.

Venkatesh, V., Morris, M.G., Davis, G.B., \& Davis, F. D. 2003. User acceptance of information technology: Toward a unified view. MIS Quarterly, pp. 425-478.

Venkatesh, V., Thong, J.Y., \& Xu, X. 2012. Consumer acceptance and use of information technology: extending the unified theory of acceptance and use of technology. MIS Quarterly, pp. 157-178.

Wang, Y.S., \& Shih, Y.W. (2009). Why do people use information kiosks? A validation of the Unified Theory of Acceptance and Use of Technology. Government Information Quarterly, Vol. 26, No. 1, pp. 158-165.

Weerakkody, V., Janssen, M., \& Dwivedi, Y. K. 2011. Transformational change and business process reengineering (BPR): Lessons from the British and Dutch public sector. Government Information Quarterly, Vol. 28, No. 3, pp. 320-328.

Zuiderwijk, A., Janssen, M., \& Dwivedi, Y.K. 2015. Acceptance and use predictors of open data technologies: Drawing upon the unified theory of acceptance and use of technology. Government Information Quarterly, Vol. 32, No. 4, pp. 429-440. 